\title{
Recent Advances in Predicting Mortality and Progression of Systemic Sclerosis-Associated Interstitial Lung Disease
}

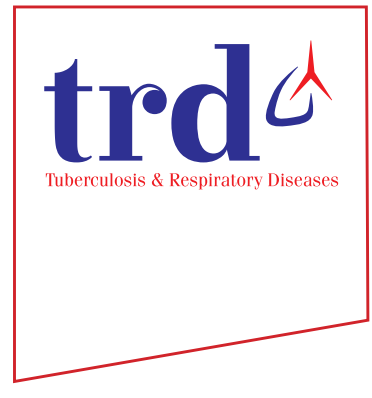

\author{
Moo Suk Park, M.D., Ph.D. \\ Division of Pulmonology, Department of Internal Medicine, Institute of Chest Diseases, Severance Hospital, Younsei University \\ Health System, Yonsei University College of Medicine, Seoul, Korea
}

Predicting mortality and progression in patients with connective tissue disease-associated interstitial lung disease (CTD-ILD) is challenging because no accurate biomarker is existed and heterogeneity in disease and patient variables are extensive ${ }^{1}$. Idiopathic pulmonary fibrosis (IPF) is a poor prognostic and chronic fibrosing interstitial lung disease (ILD) of uncertain etiology. Previous studies have showed mortality risk prediction models in IPF including age, sex, and pulmonary physiology scoring (GAP scoring system), and composite physiologic index (CPI) which are associated with mortality of $\mathrm{IPF}^{2-5}$. A prediction model in patients with CTD-ILD (ILDGAP) has been validated ${ }^{6}$. The Korean ILD Study Group in the Korean Academy of Tuberculosis and Respiratory Disease (KATRD) has created two IPF registries from 2003 to 2007 as the 2008 group, and from 2013 to 2017 as the 2018 group. The Korean ILD study group has already showed that CPI and GAP models were associated with survival of IPF patients in a nationwide cohort study ${ }^{7-9}$.

Systemic sclerosis-associated interstitial lung disease (SScILD) is similar with IPF in many clinical features and prognostic variables. Recently systematic approach to risk prediction in non-IPF chronic ILD (ILD-GAP) ${ }^{6}$ and CTD-ILD such as SSc-ILD ${ }^{10-13}$, rheumatoid arthritis (RA)-ILD ${ }^{14-16}$, and myositis-

Address for correspondence: Moo Suk Park, M.D., Ph.D.

Division of Pulmonology, Department of Internal Medicine, Institute of Chest Diseases, Severance Hospital, Yonsei University Health System,

Yonsei University College of Medicine, 50-1 Yonsei-ro, Seodaemun-gu, Seoul 03722, Korea

Phone: 82-2-2228-1955, Fax: 82-2-393-6884

E-mail: pms70@yuhs.ac

Received: Sep. 5, 2020

Revised: Sep. 7, 2020

Accepted: Sep. 9, 2020

Published online: Sep. 9, 2020

(c) It is identical to the Creative Commons Attribution Non-Commercial License (http://creativecommons.org/licenses/by-nc/4.0/). associated (MA)-ILD ${ }^{17}$, and ILD with non-small cell lung cancer (NSCLC) ${ }^{18}$ has been conducted to date, and prognostication remains challenging for clinicians. These studies derived and validated the GAP and CPI models for risk prediction of the patients with IPF $^{2}$. CPI, GAP, or ILD-GAP are applicable for evaluating the risk prediction of mortality and progression of patients with SSc-ILD, RA-ILD, and ILD-NSCLC in a similar manner as in those with IPF but the ILD-GAP risk prediction model is a poor predictor of mortality among individuals with MA-ILD ${ }^{17}$

There are no valid biomarkers to predict the progression of SSc-ILD, although Anti-topoisomerase I and several inflammatory markers are candidate biomarkers that need further evaluation $^{12}$. Despite the established relationship between SSc-ILD and morbidity and mortality, patients' clinical courses are variable and difficult to predict. There is still no consensus on screening for ILD, nor on monitoring for disease progression. Currently chest computed tomography (CT) scans remain the gold standard to screen for and diagnose SSc-ILD ${ }^{12}$.

In clinical practice, the severity of SSc-ILD may be staged based on the "Goh criteria," whereby patients have "limited" or "extensive" disease based on chest high-resolution CT scans with extent of ILD clearly less or more than $20 \%$ of involving pulmonary area, and with the use of an forced vital capacity (FVC) threshold of $70 \%$ in indeterminate cases ${ }^{19}$. A recent analysis showed that a decline in FVC or diffusing capacity for carbon monoxide $\left(\mathrm{DL}_{\mathrm{CO}}\right)$ over 2 years was a better predictor of mortality than baseline $\mathrm{FVC}$ and $\mathrm{DL}_{\mathrm{CO}}{ }^{20}$.

The progression of SSc-ILD is variable and it is important that patients are appropriately monitored after a diagnosis of ILD in SSc. Serial measurements of symptoms, physical examination, and pulmonary function tests (PFTs) are important to assess disease progression at regular clinic visits, and recent studies highlight the impact of change in PFT on mortality $^{13,20,21}$. Kaenmuang and Navasakulpong ${ }^{13}$ reported that short-term lung function had declined during the 12-month follow-up in 78 patients with progressive or stable SSc-ILD. The predictive factors in progressive SSc-ILD were male sex and no previous aspirin treatment in a single Thailand univer- 
sity hospital of seventy-eight SSc-ILD.

In the recently published SENSCIS trial, patients with SScILD treated with nintedanib had a lower rate of annual FVC decline than those receiving placebo with difference of 41 $\mathrm{mL}^{22}$. However, there is currently no consensus regarding treatment initiation or escalation. Most SSc experts make a decision on when to initiate therapy on a case-by-case basis according to their clinical experience and consideration of the risk factors for SSc-ILD progression. Better identification of which patients are at risk of progression will help to identify those who can benefit the most from early treatment ${ }^{23}$.

ILD is a major complication of SSc, and early and systematic screening of progression or deterioration is required and potentially enable treatment prior to deterioration of lung function in patients with SSc-ILD at high risk of disease progression is mandatory. Chest CT scans and serial PFTs remain important diagnostic tools, but may need to be performed regularly following SSc diagnosis to detect changes suggesting $\mathrm{ILD}^{12}$. In future, new imaging techniques and diagnostic and predictive biomarkers will play an important role in predicting mortality and progression of SSc-ILD.

\section{Conflicts of Interest}

No potential conflict of interest relevant to this article was not reported.

\section{References}

1. Winstone TA, Assayag D, Wilcox PG, Dunne JV, Hague CJ, Leipsic J, et al. Predictors of mortality and progression in scleroderma-associated interstitial lung disease: a systematic review. Chest 2014;146:422-36.

2. Ley B, Ryerson CJ, Vittinghoff E, Ryu JH, Tomassetti S, Lee JS, et al. A multidimensional index and staging system for idiopathic pulmonary fibrosis. Ann Intern Med 2012;156:684-91.

3. Wells AU, Desai SR, Rubens MB, Goh NS, Cramer D, Nicholson AG, et al. Idiopathic pulmonary fibrosis: a composite physiologic index derived from disease extent observed by computed tomography. Am J Respir Crit Care Med 2003; 167:962-9.

4. du Bois RM, Weycker D, Albera C, Bradford WZ, Costabel U, Kartashov A, et al. Ascertainment of individual risk of mortality for patients with idiopathic pulmonary fibrosis. Am J Respir Crit Care Med 2011;184:459-66.

5. du Bois RM, Albera C, Bradford WZ, Costabel U, Leff JA, Noble PW, et al. 6-Minute walk distance is an independent predictor of mortality in patients with idiopathic pulmonary fibrosis. Eur Respir J 2014;43:1421-9.

6. Ryerson CJ, Vittinghoff E, Ley B, Lee JS, Mooney JJ, Jones KD, et al. Predicting survival across chronic interstitial lung dis- ease: the ILD-GAP model. Chest 2014;145:723-8.

7. Lee SH, Park JS, Kim SY, Kim DS, Kim YW, Chung MP, et al. Comparison of CPI and GAP models in patients with idiopathic pulmonary fibrosis: a nationwide cohort study. Sci Rep 2018;8:4784.

8. Lee SH, Kim SY, Kim DS, Kim YW, Chung MP, Uh ST, et al. Predicting survival of patients with idiopathic pulmonary fibrosis using GAP score: a nationwide cohort study. Respir Res 2016;17:131.

9. Lee SH, Kim SY, Kim DS, Kim YW, Chung MP, Uh ST, et al. Comparisons of prognosis between surgically and clinically diagnosed idiopathic pulmonary fibrosis using gap model: a Korean national cohort study. Medicine (Baltimore) 2016;95:e3105.

10. Ryerson CJ, O'Connor D, Dunne JV, Schooley F, Hague CJ, Murphy D, et al. Predicting mortality in systemic sclerosisassociated interstitial lung disease using risk prediction models derived from idiopathic pulmonary fibrosis. Chest 2015;148:1268-75.

11. Wu W, Jordan S, Becker MO, Dobrota R, Maurer B, Fretheim $\mathrm{H}$, et al. Prediction of progression of interstitial lung disease in patients with systemic sclerosis: the SPAR model. Ann Rheum Dis 2018;77:1326-32.

12. Distler O, Assassi S, Cottin V, Cutolo M, Danoff SK, Denton CP, et al. Predictors of progression in systemic sclerosis patients with interstitial lung disease. Eur Respir J 2020;55:1902026.

13. Kaenmuang P, Navasakulpong A. Short-term lung function changes and predictors of progressive systemic sclerosisrelated interstitial lung disease. Tuberc Respir Dis 2020 Jul 15 [Epub].https://doi.org/10.4046/trd.2020.0043.

14. Morisset J, Vittinghoff E, Lee BY, Tonelli R, Hu X, Elicker BM, et al. The performance of the GAP model in patients with rheumatoid arthritis associated interstitial lung disease. Respir Med 2017;127:51-6.

15. Nurmi HM, Purokivi MK, Karkkainen MS, Kettunen HP, Selander TA, Kaarteenaho RL. Are risk predicting models useful for estimating survival of patients with rheumatoid arthritis-associated interstitial lung disease? BMC Pulm Med 2017;17:16.

16. Kim HC, Lee JS, Lee EY, Ha YJ, Chae EJ, Han M, et al. Risk prediction model in rheumatoid arthritis-associated interstitial lung disease. Respirology 2020 May 22 [Epub]. https://doi. org/10.1111/resp/13848.

17. Brusca RM, Pinal-Fernandez I, Psoter K, Paik JJ, Albayda J, Mecoli C, et al. The ILD-GAP risk prediction model performs poorly in myositis-associated interstitial lung disease. Respir Med 2019;150:63-5.

18. Kobayashi H, Naito T, Omae K, Omori S, Nakashima K, Wakuda K, et al. ILD-NSCLC-GAP index scoring and staging system for patients with non-small cell lung cancer and interstitial lung disease. Lung Cancer 2018;121:48-53.

19. Goh NS, Desai SR, Veeraraghavan S, Hansell DM, Copley SJ, Maher TM, et al. Interstitial lung disease in systemic scle- 
rosis: a simple staging system. Am J Respir Crit Care Med 2008;177:1248-54.

20. Volkmann ER, Tashkin DP, Sim M, Li N, Goldmuntz E, KeyesElstein L, et al. Short-term progression of interstitial lung disease in systemic sclerosis predicts long-term survival in two independent clinical trial cohorts. Ann Rheum Dis 2019;78: 122-30.

21. Goh NS, Hoyles RK, Denton CP, Hansell DM, Renzoni EA,
Maher TM, et al. Short-term pulmonary function trends are predictive of mortality in interstitial lung disease associated with systemic sclerosis. Arthritis Rheumatol 2017;69:1670-8.

22. Distler O, Highland KB, Gahlemann M, Azuma A, Fischer A, Mayes MD, et al. Nintedanib for systemic sclerosis-associated interstitial lung disease. N Engl J Med 2019;380:2518-28.

23. Cottin V, Brown KK. Interstitial lung disease associated with systemic sclerosis (SSc-ILD). Respir Res 2019;20:13. 